\title{
IMPLEMENTASI PENDIDIKAN SEKS UNDERWEAR RULES SEBAGAI UPAYA PENCEGAHAN KEKERASAN SEKSUAL DI TASIKMALAYA
}

\author{
Sofia Februanti ${ }^{1 *}$, Ai Cahyati ${ }^{1}$, Unang Arifin ${ }^{1}$ \\ ${ }^{1}$ Prodi D3 Keperawatan PoltekkesKemenkes Tasikmalaya \\ *sofiafebruanti@gmail.com
}

\begin{abstract}
Children are an investment and hope for the nation's future. But there are still many incidents of sexual violence in Indonesia. The purpose of this community service activity is to help increase the knowledge of MI Sukasirna students in preventing sexual violence. The target to be achieved is students understand the program underwear rules to prevent sexual violence. The method used is to provide sex education to students in grades 4, 5, 6; and watch videos Kiko and the hand. The number of students who took part in this activity was 61 people, grades 4, 5, and 6. Students were given pre-test questions at the beginning of the meeting and post-tests at the end of the meeting as an evaluation of the activities carried out. Facilities and infrastructure used by the projector, laptop, poster underwear rules. The results of the implementation of sex education underwear rules as an effort to prevent sexual violence in MI Sukasirna Tasikmalaya is an increase in knowledge after the activity, with an average pre-test result of 63.9, and an average post-test of 91, so that an average increase in knowledge of 27 points..
\end{abstract}

Keywords: children, underwear rules, prevention, sexual violence

\begin{abstract}
ABSTRAK
Anak merupakan investasi dan harapan masa depan bangsa. Namun masih banyak kejadian kekerasan seksual di Indonesia. Tujuan kegiatan pengabdian masyarakat ini adalah untuk membantu meningkatkan pengetahuan siswa-siswi Madrasah Ibtidaiyah (MI) Sukasirna dalam mencegah terjadinya kekerasan seksual. Target yang ingin dicapai adalah siswa- siswi mengerti program underwear rules untuk mencegah terjadinya kekerasan seksual. Metode yang digunakan adalah dengan cara memberikan pendidikan seks pada siswa- siswi kelas 4, 5, 6; serta menonton video kiko and the hand. Jumlah siswa yang mengikuti kegiatan ini sebanyak 61 orang, kelas 4, 5, dan 6. Siswa diberikan soal pre test pada awal pertemuan dan post test pada akhir pertemuan sebagai evaluasi terhadap kegiatan yang dilakukan. Sarana dan prasarana yang digunakan proyektor, laptop, poster underwear rules. Hasil kegiatan implementasi pendidikan seks underwear rules sebagai upaya pencegahan kekerasan seksual di MI Sukasirna Tasikmalaya adalah terjadi peningkatan pengetahuan setelah kegiatan, dengan hasil rata- rata pre tes 63,9 , dan rata- rata post test 91 , sehingga rata-rata peningkatan pengetahuan sebanyak 27 poin.
\end{abstract}

Kata kunci: anak, underwear rules, pencegahan, kekerasan seksual

38 Edukasi Masyarakat Sehat Sejahtera (EMaSS) : Jurnal Pengabdian kepada Masyarakat Volume 2 No.1 Tahun 2020 


\section{I.PENDAHULUAN}

Kekerasan seksual dapat terjadi pada anak perempuan dan laki- laki. Indonesia ditengarai masih teramat rentan menjadi korban kekerasan, baik fisik maupun seksual. menurut Kemenkes \& Unicef (2007), puskesmas sebagai sarana pelayanan kesehatan dasar atau primer dapat menerima, menangani kasus kekerasan seksual pada anak atau apabila diperlukan merujuk ke rumah sakit atau institusi terkait untuk mendapatkan penanganan lebih lanjut. Puskesmas sebagai sarana pelayanan kesehatan primer belum memiliki program khusus dalam melakukan pencegahan kekerasan seksual pada anak (Kartilah, Februanti, Sakti, \& Hidayat, 2018). Padahal jika puskesmas memiliki program khusus dalam pencegahan kekerasan seksual, dapat dimasukkan ke dalam program Usaha Kesehatan Sekolah (UKS) SD atau sederajat. Hal ini dapat dilakukan sebagai upaya pencegahan kekerasan seksual pada anak sekolah.

Kekerasan seksual pada anak dapat didefinisikan dengan segala bentuk penganiayan seksual pada anak, komentar yang tidak diinginkan, paksaan untuk memenuhi kepuasan seksualitas seseorang oleh siapapun, termasuk cumbuan pada payudara atau organ genital, paparan aktivitas seksual, dan oral, anal, penis atau penetrasi vagina (Hu et al., 2018; Osofsky \& Groves, 2018; Florentin \& Hantoro, 2018). Dampak yang dapat timbul pada anak korban kekerasan seksual diantaranya dapat mengganggu pertumbuhan dan perkembangan anak, dan menempatkan anak-anak berisiko mengalami beragam gangguan mental dan emosional, termasuk kecemasan (misalnya gangguan panik, OCD dan PTSD), depresi, kemarahan, distorsi kognitif, stres posttraumatic, disosiasi, gangguan identitas, mempengaruhi disregulasi, masalah interpersonal, penyalahgunaan zat, mutilasi diri, bulimia, perilaku seksual yang tidak aman atau disfungsional, Somatisasi, agresi, suicidality, dan gangguan kepribadian (Carson, Foster, \& Chowdhury, 2014). Oleh karenanya dibutuhkan upaya pencegahan kekerasan seksual.

Upaya pencegahan yang efektif antara lain dengan memberikan pendidikan seks berupa penyuluhan tentang pencegahan pelecehan dan kekerasan seksual, pemahaman kesehatan reproduksi secara dini pada anak, orang tua, dan guru melalui program underwear rules (Budiyono, Ramadani, \& Mahrosi, 2018; Persada \& Ayuningtyas, 2015; Ramadani \& Budiyono, 2018; Wijhati \& Suharni, 2018). Program underwear rules diharapkan dapat membuat anak menjaga dirinya dari orang yang akan berniat melakukan kejahatan seksual sehingga anak dapat melakukan pencegahan dan perlindungan terhadap dirinya (Nurbaya \& Qasim, 2018; Andriani \& Nahdliyah, 2018).

39 Edukasi Masyarakat Sehat Sejahtera (EMaSS) : Jurnal Pengabdian kepada Masyarakat Volume 2 No.1 Tahun 2020 
MI Sukasirna merupakan Madrasah Ibtidaiyah, setara dengan sekolah dasar (SD) yang berada di wilayah kerja puskesmas Sambong, Mangkubumi. Berdasarkan data KPAD Kota Tasikmalaya (2018), jumlah kasus tertinggi berada di kecamatan Mangkubumi, kekerasan seksual pada anak perempuan sebanyak 4 orang dan laki- laki 2 orang, usia korban kekerasan antar 7-12 tahun. MI Sukasirna memiliki Usaha Kesehatan Sekolah (UKS) dengan ruangan yang seadanya, dan belum memiliki program khusus untuk mencegah terjadinya kekerasan seksual pada anak. Berdasarkan fenomena tersebut maka dipandang perlu untuk melakukan implementasi pendidikan seks underwear rules sebagai upaya pencegahan kekerasan seksual.

\section{METODE}

Metode yang digunakan selama proses pembelajaran di antaranya adalah: Ceramah singkat dan tanya jawab, menonton video kiko and the hand, bermain boneka tentang underwear rules. Siswa diberikan pertanyaan pre tes untuk mengukur kemampuan atau pengetahuan sebelum pemberian pendidikan kesehatan underwear rules kemudian siswa diberikan pendidikan kesehatan underwear rules sebagai upaya pencegahan kekerasan seksual. Setelah kegiatan, siswa diberikan pertanyaan post tes untuk mengukur kemampuan atau pengetahuan setelah pemberian pendidikan kesehatan underwear rules.

\section{HASIL DAN PEMBAHASAN}

Kegiatan Implementasi pendidikan seks underwear rules sebagai upaya pencegahan kekerasan seksual di MI Sukasirna Tasikmalaya diikuti oleh 61 orang siswa kelas 4, 5, dan 6, diikuti guru kelas, perwakilan Komisi Perlindungan Anak (KPAD) dalam penyampaian materi. Kegiatan ini dilaksanakan 4 hari. Kegiatan dilaksanakan selama 4 hari. Berikut evaluasi hasil kegiatan Implementasi pendidikan seks underwear rules sebagai upaya pencegahan kekerasan seksual di MI Sukasirna Tasikmalaya. 
Tabel 1. Distribusi Responden Berdasarkan Karakteristik Responden (n=61)

\begin{tabular}{lcc}
\hline \multicolumn{1}{c}{ Variabel } & n & \% \\
\hline Jenis kelamin & & \\
Perempuan & 28 & 45,9 \\
Laki- laki & 33 & 54,1 \\
\hline Kelas & & \\
IV & 19 & 31,1 \\
V & 22 & 36 \\
VI & 20 & 32,7 \\
\hline
\end{tabular}

Tabel 2. Distribusi Responden Berdasarkan Usia (n=61)

\begin{tabular}{ccc}
\hline Variabel & Mean & Min-maks \\
\hline Usia & 10,18 & $9-13$ \\
\hline
\end{tabular}

Tabel 3. Distribusi Responden Berdasarkan Tingkat Pengetahuan

\begin{tabular}{ccccc}
\hline \multirow{2}{*}{ Pengetahuan } & \multicolumn{2}{c}{ Pre test } & \multicolumn{2}{c}{ Post test } \\
\cline { 2 - 5 } & n & \% & n & \% \\
\hline Baik & 10 & 16,3 & 57 & 93,4 \\
\hline Cukup & 39 & 63,9 & 4 & 6 \\
\hline Kurang & 12 & 19,6 & 0 & 0 \\
\hline & 61 & 100 & 61 & 100 \\
\hline
\end{tabular}

Anak merupakan generasi penerus bangsa. Anak yang sehat baik secara bio, psiko, sosio, dan spiritual merupakan dambaan semua orang tua. Namun, banyak kejadian yang dapat menimpa anak seperti kekerasan seksual. Kekerasan seksual dapat terjadi pada anak dimana pun seperti di rumah, lingkungan sekolah, tempat bermain atau dimana saja. Oleh karena itu, lingkungan di sekitar anak sekolah memiliki peran untuk mencegah kekerasan seksual. Salah satunya dengan membekali anak pengetahuan, nilai- nilai, sikap, keterampilan yang berhubungan dengan anatomi tubuh, hubungan personal, dan seksualitas, atau memberikan pendidikan seksual pada anak sejak dini. Sekolah juga merupakan tempat anak bersosialisasi dan berinteraksi dengan orang dewasa lain yang bukan keluarganya sehingga memiliki banyak contoh nyata dalam belajar pendidikan seksual (Felicia \& Pandia, 2017).

Pendidikan seks adalah pemberian pengetahuan yang benar dan menyiapkannya untuk beradaptasi secara baik dengan sikap-sikap seksual di masa depan kehidupannya. Pemberian pengetahuan ini menyebabkan seseorang memperoleh kecenderungan logis yang benar terhadap masalah- masalah seksual dan reproduksi (Kalele, 2019). Pendidikan seks untuk anak seharusnya sudah dimulai sejak usia dini, tepatnya saat usia 3-4 tahun karena pada usia ini anak sudah bisa 
melakukan komunikasi dua arah dan dapat mengerti mengenai organ tubuh mereka dan dapat pula dilanjutkan pengenalan organ tubuh internal. Masyarakat beranggapan pendidikan seks dianggap tabu. Namun mengajarkan pendidikan seks pada anak harus diberikan agar anak tidak salah melangkah dalam hidupnya (Kalele, 2019).

Penyampaian pendidikan seksual pada anak dapat dilakukan dengan berbagai macam media. Media pendidikan seksual dapat berupa media cetak atau media elektronik (Maharani \& Sanyata, 2019). Pada kegiatan pengabdian masyarakat yang telah dilakukan di MI Sukasirna Tasikmalaya, metode yang digunakan adalah dengan memberikan pendidikan kesehatan berupa underwear rules melalui media dongeng dan boneka tangan serta menggunakan laptop dan LCD. Dengan penyampaian materi pendidikan seks underwear rules menggunakan media, terdapat peningkatan pengetahuan sebelum dan sesudah penyampaian materi pada siswa MI tentang underwear rules. Dengan adanya peningkatan pengetahuan pada siswa MI, diharapkan dapat mencegah terjadinya kekerasan seksual.

\section{SIMPULAN}

Setelah dilakukan kegiatan pendidikan kesehatan underwear rules sebagai upaya pencegahan kekerasan seksual maka terjadi peningkatan pengetahuan siswa MI Sukasirna Tasikmalaya tentang pendidikan seks underwear rules sebagai upaya pencegahan kekerasan seksual.

\section{UCAPAN TERIMAKASIH}

Tim Pengabdian Kepada Masyarakat mengucapkan terima kasih kepada Direktur dan Kapuslitbang Poltekkes Kemenkes Tasikmalaya, MI Sukasirna Tasikmalaya, dan KPAD Kota Tasikmalaya yang telah membantu kegiatan pengabdian kepada masyarakat berlangsung.

\section{DAFTAR PUSTAKA}

Andriani, Z. Z. D., \& Nahdliyah, A. (2018). Upaya Pencegahan Kekerasan Seksual Pada Anak Melalui Pendidikan Kesehatan Reproduksi Sejak Dini. Loyalitas Jurnal Pengabdian Kepada Masyarakat, I(2), 126-148.

Budiyono, A., Ramadani, S. D., \& Mahrosi. (2018). PENINGKATAN KESADARAN DIRI MENGHADAPI RESIKO. In seminar nasional hasil pengabdian kepada masyarakat (SENIAS) 2018 (pp. 245-248). Madura: Universitas Islam Madura. 
Carson, D. K., Foster, J. M., \& Chowdhury, A. (2014). Sexual Abuse of Children and Youth in India An Anthropological Perspective. The Oriental Anthropologist, 14, no 2(January), 149-170.

Felicia, J. P., \& Pandia, W. S. S. (2017). Persepsi Guru TKI terhadap Pendidikan Seksual Anak Usia Dini berdasarkan Health- Belief Model. Jurnal Pendidikan Anak, 6(1), 71-82.

Florentin, V., \& Hantoro, J. (2018, December 27). KPAI: Guru Jadi Pelaku Kekerasan Seksual Terbanyak di Sekolah. Tempo.co. Retrieved from https://nasional.tempo.co/read/1159418/kpai-guru-jadi-pelaku-kekerasan-seksualterbanyak-di-sekolah

Hu, M.-H., Huang, G.-S., Huang, J.-L., Wu, C.-T., Chao, A.-S., Lo, F.-S., \& Wu, H.-P. (2018). Clinical characteristic and risk factors of recurrent sexual abuse and delayed reported sexual abuse in childhood. Medicine (Baltimore), 97(14).

Kalele, R. D. (2019). Efektivitas Program Underwear Rule Untuk Meningkatkan Pengetahuan Orangtua (Ibu) Mengenai Bahaya Kekerasan Seksual pada Anak. UIN Suska Riau.

Kartilah, T., Februanti, S., Sakti, B., \& Hidayat, U. A. (2018). The Role of Community Health Centres (PUSKESMAS) in the implementation of sexual violence for school age children in elementary school. JMCRH, 1(2), 341-350.

Kemenkes, \& Unicef. (2007). Pedoman rujukan kasus kekerasan terhadap Anak Bagi Petugas Kesehatan. Jakarta: unicef.

KPAD Kota Tasikmalaya. (2018). DATA KASUS KOMISI PERLINDUNGAN ANAK DAERAH KOTA TASIKMALAYA. Tasikmalaya.

Maharani, L. N., \& Sanyata, S. (2019). Media for sex education in elementary school: Which one is better. Psychology, Evaluation, and Technology in Educational Research, 1(2), 73-80.

Nurbaya, S., \& Qasim, M. (2018). Penerapan pendidikan seks (underwear rules) terhadap pencegahan kekerasan seksual pada anak dan orang tua di SD negeri 52 Welonge kabupaten Soppeng. Media Kesehatan Politeknik Kesehatan Makasar, XIII(2), 19-27.

Osofsky, J. D., \& Groves, B. M. (2018). Violence and Trauma in the Lives of Children. Boston: ABC-CLIO.

Persada, A. G., \& Ayuningtyas, N. P. D. (2015). Pencegahan Pelecehan dan kekerasa Seksual Pada Anak-Anak Di SDN Gejayan. Jurnal INovasi Dan Kewirausahaan, 4(3), 211-214. https://doi.org/2089-3086

Ramadani, S. D., \& Budiyono, A. (2018). PENINGKATAN PEMAHAMAN KESEHATAN REPRODUKSI DALAM BINGKAI ISLAM BAGI SISWA SEKOLAH DASAR DI DESA PALALANG KECAMATAN PAKONG, PAMEKASAN. In Seminar Nasional Hasil Pengabdian kepada Masyarakat (SENIAS) (pp. 261-266). Madura: Universitas Islam Madura.

Wijhati, E. R., \& Suharni. (2018). Pelatihan Pendidikan Seks Anak Usia Dini pada Kader “ Aisyiyah Ranting Pandeyan Kecamatan Umbulharjo. Aksiologiya: Jurnal Pengabdian Kepada Masyarakat, 2(1), 82-87. 